\title{
Microstructural Investigation of $\mathrm{Al}-\mathrm{Mg} / \mathrm{B}_{4} \mathrm{C}$ Composite deformed at elevated temperature
}

\author{
M. Rezayat ${ }^{\text {abc }}$, M.H. Parsa ${ }^{b^{*}}$, H. Mirzadeh ${ }^{\text {b }}$ and J.M. Cabrera ${ }^{c}$ \\ ${ }^{a}$ Department of Materials Engineering, Sahand University of Technology, P. O. Box 51335-1996, Tabriz, Iran \\ ${ }^{\mathrm{b}}$ School of Metallurgy and Materials Engineering, College of Engineering, University of Tehran, P.O. Box 11155-4563, \\ Tehran, Iran \\ c Departamento de Ciencia de los Materiales e Ingeniería Metalúrgica, EEBE, Universitat Politècnica de Catalunya, \\ c/Eduard Maristany 10-14, 08019 - Barcelona, Spain \\ *Corresponding Author
}

\begin{abstract}
The microstructure evolution of $\mathrm{Al}-3 \mathrm{wt} . \% \mathrm{Mg}$ reinforced with $10 \mathrm{vol} \% \mathrm{~B}_{4} \mathrm{C}$ during isothermal compression at temperatures ranging 300 to $500{ }^{\circ} \mathrm{C}$ at strain rates of 0.001 to $10 \mathrm{~s}^{-1}$ was investigated by electron backscatter diffraction (EBSD). According to the results, at strain rates lower than $0.01 \mathrm{~s}^{-1}$ and temperatures higher than $400{ }^{\circ} \mathrm{C}$, the grain size distribution in the microstructure is uniform, dynamic recovery is the predominant softening mechanism and continues recrystallization through lattice rotation is responsible for grain refinement. However, during deformation at higher strain rates or lower temperatures, deformation zones appeared in special locations around particles where microstructure is formed by recovered and hardened grains, and particle stimulating nucleation leaded to partially discontinues dynamic recrystallization which in turns promoted finer average grain and sub-grain size than those in single phase Al-Mg alloy. Moreover, it was found that the variation of grain and subgrain size with deformation parameters (Zener-Holloman parameter $(Z)$ ) can be described by a power law type equation rather than by an initially expected exponential expression.
\end{abstract}

Keywords: Hot deformation; Al-Mg alloy; Metal Matrix Composite; Electron Back Scatter Diffraction; Dynamic restoration 


\section{Introduction}

Aluminum matrix composites (AMCs) have found various applications in different industries based on their supreme properties. According to their fabrication routes, either powder metallurgy or casting, deformation at elevated temperatures is usually applied to reduce the internal defects [1]. This additional forming operation in turns provides an opportunity to design the matrix microstructure in terms of grain size and texture [2]. Based on the deformation condition, i.e., temperature, strain and strain rate, the occurrence of different restoration mechanisms such as dynamic recrystallization (DRX), dynamic recovery (DRV), and also post dynamic and static phenomena, can take place. Appropriated control of such phenomena can be used to predict and control the microstructure evolution [3].

Presence of the second phase particles in the microstructure can make the situation more complicated. It has been shown that coarse particles lead to grain refinement by particle stimulating nucleation (PSN) and fine particles by a Zener pining effect, may keep under control or avoid the recrystallization and even grain growth during deformation sequences [46]. Moreover, it has been found that microstructure evolution of metal matrix composites (MMCs) during hot deformation can be also accompanied by particle fracture, particle-matrix interface debonding, flow localization and instability, and matrix cracking [7-9]. It should be noted that although the second phase affects the microstructure evolution, it has been observed that the softening mechanisms of composites are similar to those of single phase alloys and they mainly depend on the deformation condition $[5,10]$. In other words, by decreasing Zener-Hollomon parameter (Z), high dislocations density area around particles, i.e., deformation zones, will be annihilated by DRX or DRV, likewise restoration mechanisms in aluminum alloys at lower $Z$ values [6]. In addition to deformation condition, the domination of recrystallization or recovery depends on alloying elements [2]. For example $\mathrm{Mg}$ as an alloying element in solid solution reduces the staking fault energy which postpones the recovery processes [11,12].

Several researches has been conducted on hot deformation of Al-Mg alloys as a widely applicable group of aluminum alloys, nevertheless, the occurrence of dynamic restoration mechanisms is still under debate [13-17]. For example, Sheppard et. al. [18] reported that softening mechanism depends on $\mathrm{Mg}$ solute and it will not happen when $\mathrm{Mg}$ is less than 3 wt.\%, whereas, Ihara et. al. [19] observed DRXed grains in Al-3Mg alloy. Moreover, the effects of the second phase on these mechanisms in Al-Mg have been less addressed so far and although it was reported that during hot deformation of $\mathrm{Al}-\mathrm{Mg}$ containing second phases 
particles, DRX can partially occurs [17,20], there is not a comprehensive study about the impact of coarse particles on the microstructure evolution of this alloys in the literature.

Therefore, the aim of this research is to investigate the microstructure evolution and grain refinement mechanisms during high temperature deformation of $\mathrm{Al}-3 \mathrm{Mg}$ reinforced with $\mathrm{B}_{4} \mathrm{C}$ particles for a wide range of temperature and strain rate values.

\section{Experiment}

$\mathrm{Al}-3 \mathrm{wt} . \% \mathrm{Mg}$ alloy and $\mathrm{Al}-3 \mathrm{wt} . \% \mathrm{Mg} / \mathrm{B}_{4} \mathrm{C}$ composites with average particle size of $80 \mu \mathrm{m}$ and volume fraction of $10 \%$ were fabricated from stir-casting followed by hot extrusion as described in details in a previous work [21]. Chemical compositions of $\mathrm{Al}-3 \mathrm{Mg}$ alloy and composite according to Electron Probe Micro-Analyzer (Cameca SX100) and Quantometer analysis, were around $2.9 \mathrm{Mg}, 0.15 \mathrm{Fe}$, and $0.2 \mathrm{Si}$ (in wt.\%).

Single-hit hot compression tests of cylindrical specimens with length of 11.5 and $10 \mathrm{~mm}$ and diameter of 7.4 and $5 \mathrm{~mm}$ were carried out in an Instron 4507 universal deformation machine and a Baehr DIL-805 deformation dilatometer, respectively. Deformations were performed at temperatures of $300^{\circ} \mathrm{C}, 400^{\circ} \mathrm{C}$ and $500^{\circ} \mathrm{C}$ at constant strain rates ranging $10^{-3}$ to $10 \mathrm{~s}^{-1}$.

In order to examine the deformed microstructures by electron backscatter diffraction (EBSD), a Thermal-Field-Emission Scanning Electron Microscope (Jeol 7001f-0.1-30 kV) was employed. For this purpose samples were prepared according to standard metallographic procedures. In order to distinguish between high angle grain boundaries (represented by black lines) and low angle grain boundaries (represented by green lines) a misoriention threshold of $15^{\circ}$ was selected. Then, if the average misorientation angle within a grain exceeded the minimum angle to define a subgrain, i.e., $3^{\circ}$, the grain was classified as deformed grain. If internal average misorientation was under $3^{\circ}$ but the misorientation from one part to other part of the grain was above $3^{\circ}$ (i.e., grain consists of subgrains), the grain was consideredas recovered. All the remaining grains were classified as recrystallized.

\section{Result and discussion}

\subsection{Grain refinement mechanisms - impact of strain rate}

Fig. 1 represents the microstructure of $\mathrm{Al}-\mathrm{Mg}$, reinforced with $10 \mathrm{vol} . \% \mathrm{~B}_{4} \mathrm{C}$, deformed at $400{ }^{\circ} \mathrm{C}$ at different strain rates. As it can be seen, at low strain rate, i.e., $10^{-3} \mathrm{~s}^{-1}$, grain boundaries are somehow serrated. This is due to formation of high dislocation density areas and consequently low angle grain boundary (LAGB) behind of former grain boundaries, 
which restrict grain boundaries movement by formation of triple point junction with high angle grain boundaries (HAGB) [22]. Increase in strain rate results in activation of more dislocations to accommodate deformation which in turn leads to the formation of more LAGBs and smaller subgrain size. This also results in a heterogonous distribution of subgrains. In other words, at increasing strain rates, subgrains are mainly located around boundaries. The smaller subgrains and finer grain boundary serrations can be also noticed in isolated grains presented in Fig. 2.
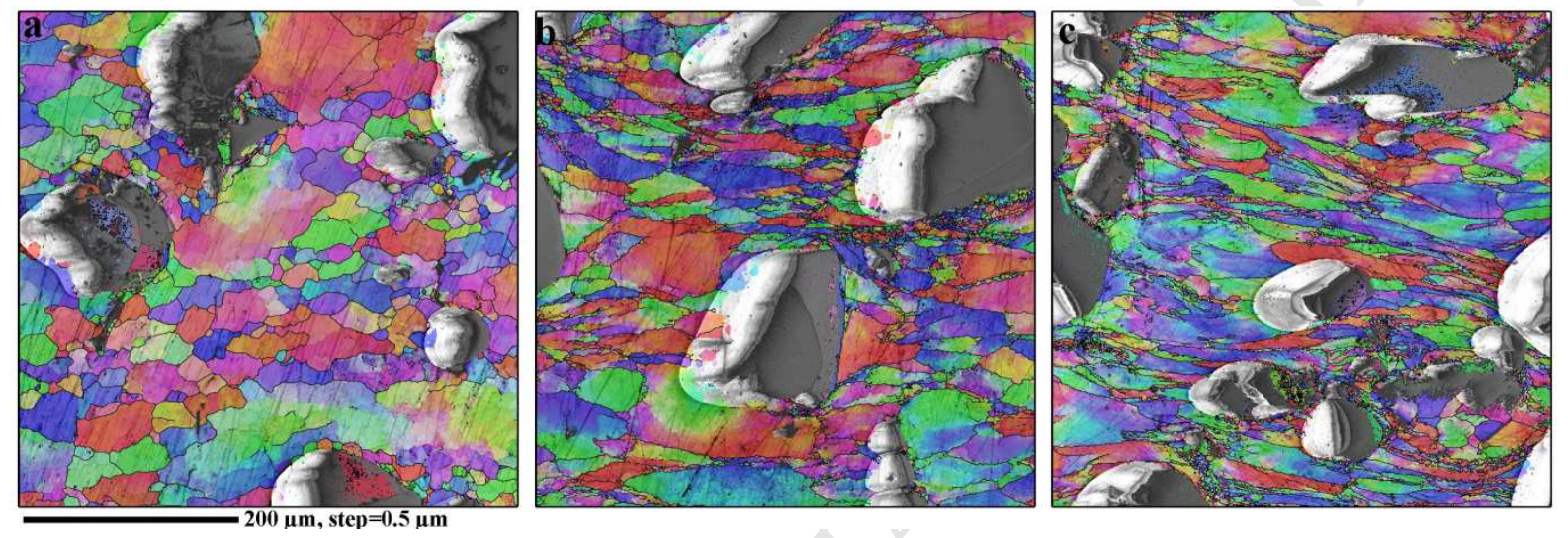

Fig. 1: EBSD Micrographs of $\mathrm{Al}-\mathrm{Mg} / 10 \% \mathrm{~B}_{4} \mathrm{C}$ samples deformed $400^{\circ} \mathrm{C}$ up to strain of 0.7 at a strain rate of (a) $10^{-3} \mathrm{~s}^{-1}$, (b) $10^{-1} \mathrm{~s}^{-1}$, and (c) $10^{1} \mathrm{~s}^{-1}$. It should be noted that compression direction is $\mathrm{Y}$ direction.

During deformation at low strain rate, where grain boundary sliding might be one of the deformation mechanisms, formation of serration on grain boundaries limits the boundary sliding and causes the formation of plastic accommodation zones around serrations [22]. As a result, some strain induced subgrains appear near the boundaries, which can be converted to high angle grain boundaries by further straining. This phenomena has been named lattice rotation continues recrystallization (LRDRX) [22]. Some of these grains are shown in Fig. 2a and as it is evident, their orientation is different from the initial grain.

Recrystallized grains as well as recovered and hardened grains are identified with different colors for all the microstructures in Fig 3a-f. According to Fig.3a, the full annealed microstructure contains recrystallized grains and recovered grains (subgrains). The identification of grains as recovered ones is based on presence of LAGBs inside the grains which is due to the rotation of grains and hence converting HAGBs to LAGBs during annealing. As it is clear in Fig. $3 \mathrm{~b}$ and c, after deformation at strain rates of $10^{-3}$ and $10^{-2} \mathrm{~s}^{-1}$, recrystallized grains are uniformly distributed into the microstructure and there is not any 
preferential site where they appear, either between particles or far away from the particles. Based on the mentioned recrystallization mechanism and due to the formation of finer subgrains, an increase in strain rate up to $10^{-2} \mathrm{~s}^{-1}$ resulted in smaller recrystallized grains.

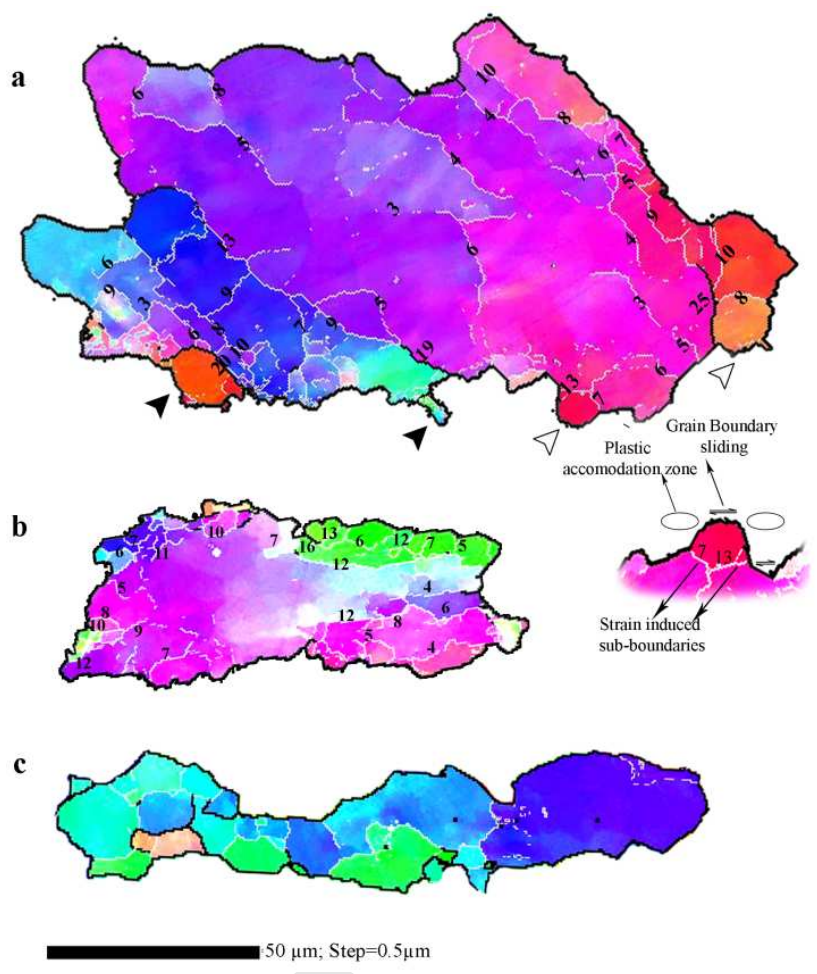

Fig. 2: Isolated grains from microstructures deformed at $400^{\circ} \mathrm{C}$ up to strain of 0.7 at a strain rate of (a,c) $10^{-3} \mathrm{~s}^{-1}$ and (b) $10^{-2} \mathrm{~s}^{-1}$ (white lines: LAGBs, black lines: HAGBs, white arrows: potentially grains for LRDRX and black arrows: LRDRXed grains).

On the other hand the presence of elongated grains in the microstructure of samples deformed at higher strain rates $\left(10^{-1} \mathrm{~s}^{-1}\right)$ indicates that grain boundary sliding is limited and deformation is mainly accommodated by dislocation glide based mechanisms. However, in this latter condition, some work hardened grains and also some fine recrystallized grains are located around particles as shown in Fig. 3d. It is well known that in metal matrix composites reinforced with large particles, the main strengthening mechanism is load transferred from matrix to hard particles [23]. This feature in turns leads to the formation of stress gradient from particles to the matrix which will be relaxed by geometrically necessary dislocation at low strains. Continued straining, based on difference between elastic modulus of particle and matrix, will lead to the appearance of a deformation zone (DZ) around particles with high 
dislocation density and large misorientation gradient. These high energy areas are suitable sites for nucleation of new recrystallized grains promoting the so-called particle stimulating nucleation (PSN).
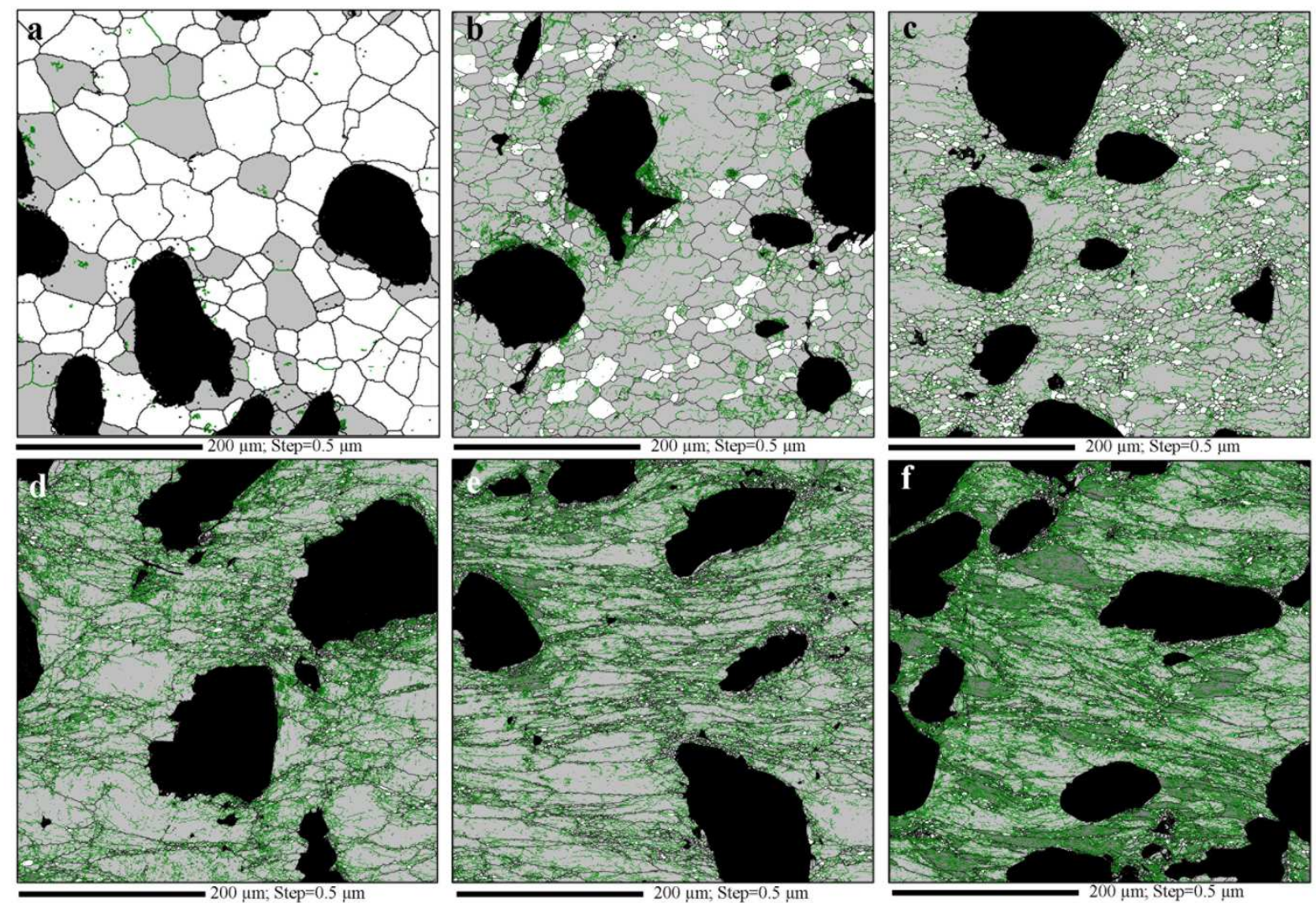

Fig. 3: Identifying recrystallized (white), recovered (gray), and work hardened (dark gray) grains for $\mathrm{Al}-3 \mathrm{Mg}$ reinforced with $10 \% \mathrm{~B}_{4} \mathrm{C}$ (black) in (a) annealed and deformed at $400^{\circ} \mathrm{C}$ up to strain of 0.7 at a strain rate of (b) $10^{-3} \mathrm{~s}^{-1}$, (c) $10^{-2} \mathrm{~s}^{-1}$, (d) $10^{-1} \mathrm{~s}^{-1}$, (e) $1 \mathrm{~s}^{-1}$ and (f) $10 \mathrm{~s}^{-1}$. Green lines account for LAGB, while black lines for HAGB.

To investigate the occurrence of PSN, the misorientation of grain boundaries for the single phase alloy and the composite one is compared in Fig. 4a,b. It is clear that more HAGBs are present in the composite microstructure than single phase alloy. Considering the fraction of HAGBs at the deformation zone near particles and the corresponding fraction of HAGBs in the matrix far away from particles, it seems that DZs are responsible for increasing the fraction of HAGBs in the overall composite microstructure. Presence of such value of HAGBs around particles, is evidenced by several small grains (Fig. 4c and d) which can be resulted from a DRX process. 
According to the EBSD micrographs and location of DRXed grains, it seems also that deformation zones are not uniformly distributed around particles. To identify deformation zone areas, the variation of misorientation from the interface of particle-matrix toward the matrix was investigated. As it can be seen in Fig. 5, Y direction, i.e., the compression direction, shows higher misorientation in comparison with $\mathrm{X}$ direction. Based on the fact that misorientations can be related to geometrical needed dislocation density [24], this area provides the energy required for the activation energy for DRX to occur. Besides, as illustrated in Fig 3 and 4, initial grains at these areas are elongated, and in some cases fractured, which results in the formation of some small work hardened grains, especially at higher deformation rates.
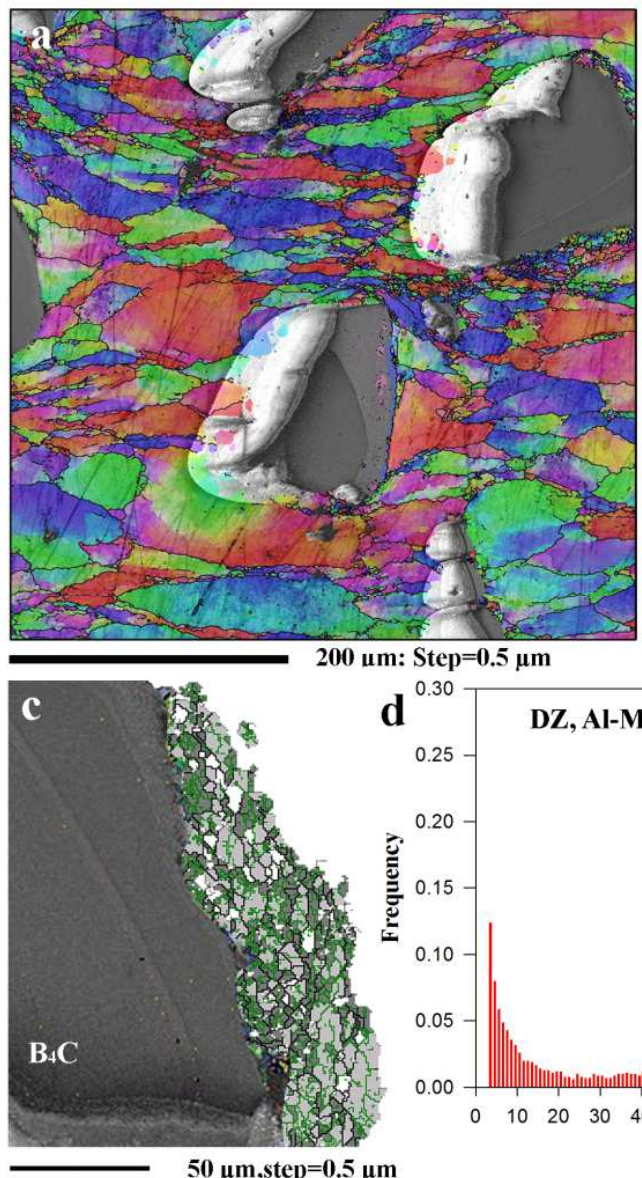

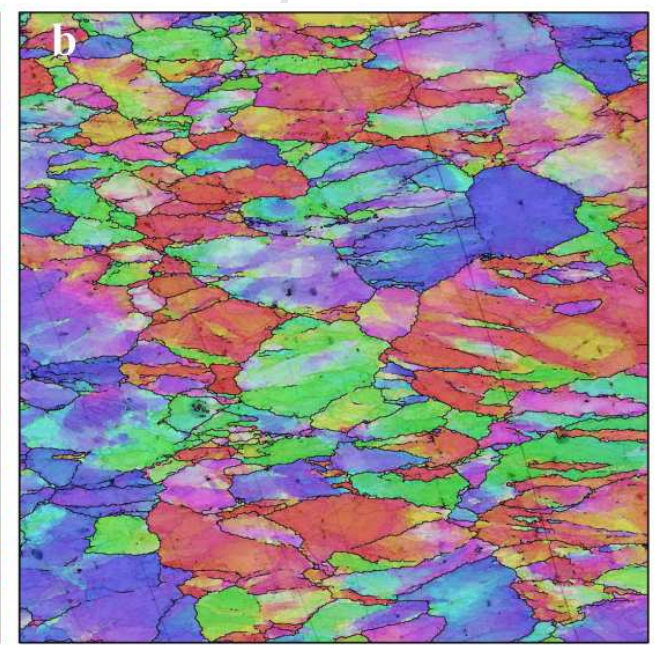

$200 \mu \mathrm{m} ;$ Step $=0.5 \mu \mathrm{m}$

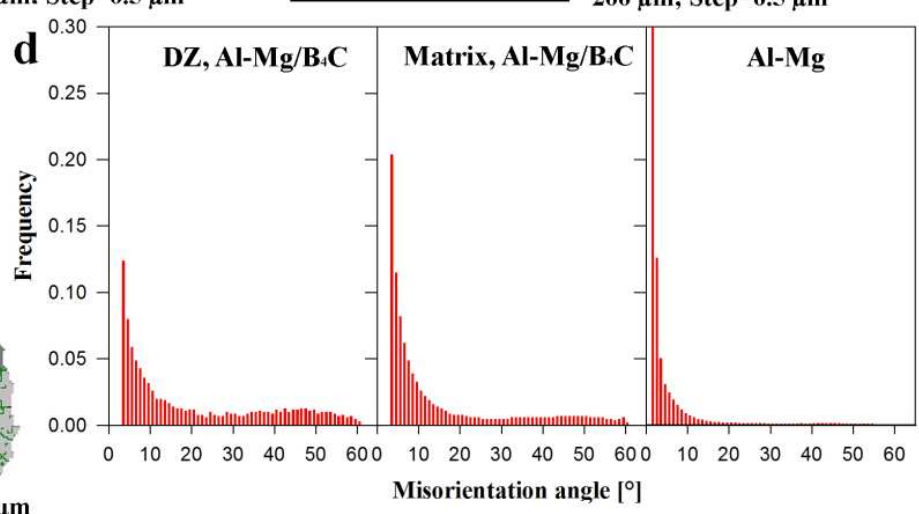

Fig. 4: Comparing microstructures of $(\mathrm{a}, \mathrm{c}) \mathrm{Al}-3 \mathrm{Mg} / 10 \% \mathrm{~B}_{4} \mathrm{C}$ composite and (b) $\mathrm{Al}-3 \mathrm{Mg}$ single phase alloy, deformed at $400^{\circ} \mathrm{C}$ up to strain of 0.7 with rate of $10^{-1} \mathrm{~s}^{-1}$, and (d) their corresponding grain boundaries misorientation graphs in different areas. 
Nevertheless, as already mentioned, some DRXed grains can be also found far away from particles. Considering the high resolution EBSD micrographs displayed in Fig. 6, it seems that the bulging mechanism can be considered as a one of the nucleation mechanisms of DRX. According to this mechanism, limited migration of serrated grain boundaries leads to formation of a low dislocation density area behind them which is accompanied by formation of LAGB [22]. This area can act as nuclei for recrystallization. Some of these new grains are shown in Fig. 6. As well, some DRXed grains located at triple point junctions can be also noticed in this latter figure.
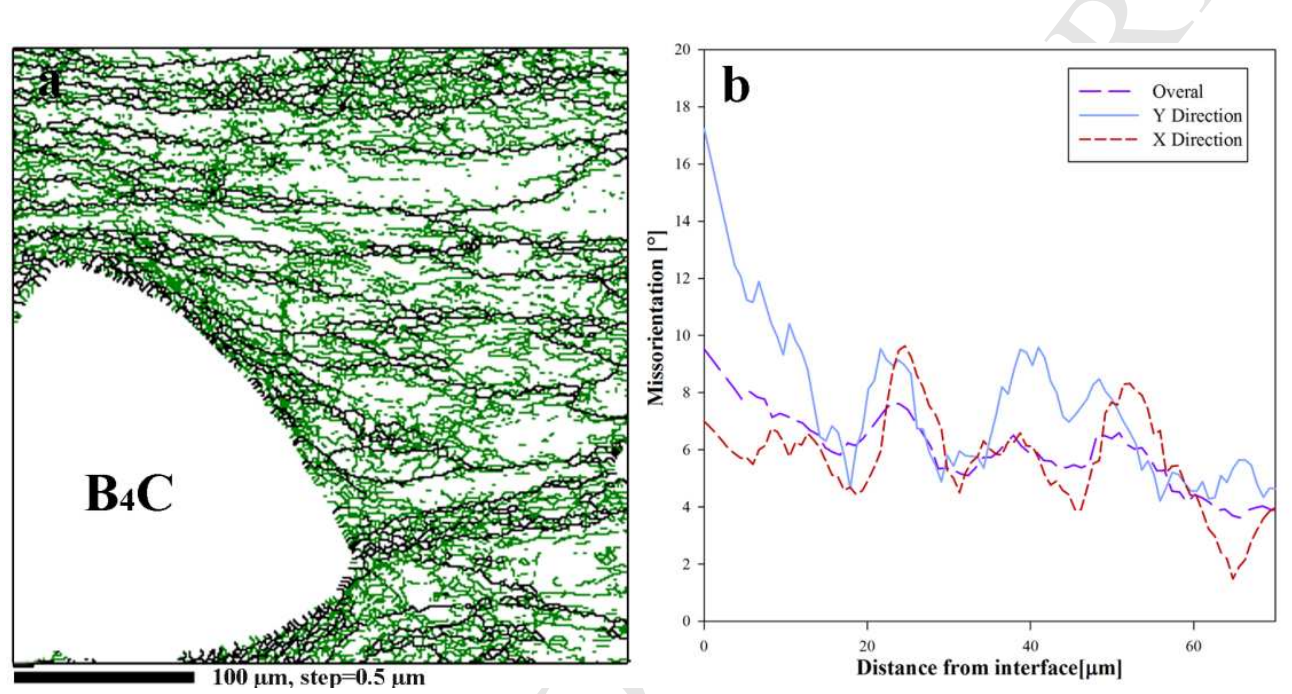

Fig.5: Variation of misorientation from particle-matrix interface to matrix in two directions, parallel and perpendicular to the compression axes, $\mathrm{Y}$ and $\mathrm{X}$ respectively, with the corresponding micrographs accounting for HAGBs and LAGBs. Sample deformed at $400^{\circ} \mathrm{C}$ up to strain of 0.7 at a strain rate of 1 $\mathrm{s}^{-1}$.

Deformation at strain rates of $1 \mathrm{~s}^{-1}$ and $10 \mathrm{~s}^{-1}$ made grains more elongated and subgrains even smaller. However, fine DRXed grains still can be identified around the particles, although in lower amount than at slower strain rates. It has been reported that increasing the strain rate also increases the critical dislocation density for the onset of DRX, or in other words, by increasing strain rate, more deformation is required for DRX, i.e., $\rho_{c}=\left(2 \gamma_{b} \dot{\varepsilon} / K M L G b^{5}\right)^{1 / 3}[25]$. This is in accordance with Fig. 7 where once can notice that the overall fraction of DRXed grains decreases as the strain rate is increased. However, the fraction of DRXed grains located around particles represents a maximum value at a strain rate of $10^{-1} \mathrm{~s}^{-1}$. This fact is due to the activation of the PSN mechanism in a limited range of the Zener - Hollomon $(Z)$ parameter. At very low values of $Z$ s (low strain rates), where the continuous recrystallization 
mechanism is dominant, DZs are not formed or appeared a limited area around particle. In order to investigate the extension of the deformation zone DZ in to the matrix, at different deformation conditions, the variation of misorientation from particle to matrix was plotted in Fig. 8. Considering these results, DZ is quite small and limited at low $Z$ values. However, at high Zs, DZ is developed inside the matrix and around the particle. The former is due to flow localization which can occur during deformation at lower $Z$. Therefore, the reason as why PSN is limited at low $Z$ is the formation of smaller DZ and occurrence of dynamic recovery and reduction of stored energy in such condition. It also has been stated that PSN will not be so effective during hot deformation due to the fact that dislocations may bypass particles without forming a DZ or due to the development of a dislocation structure in the grains [6].
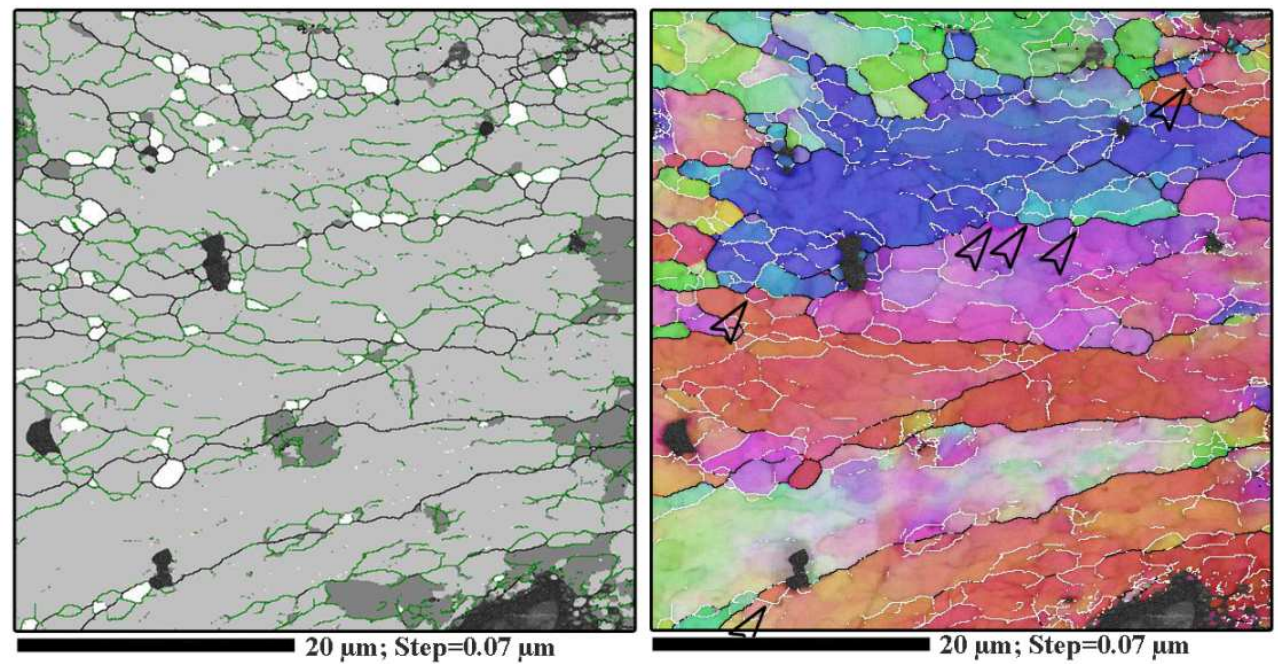

Fig. 6: Location and orientation of small DRXed grains in a microstructure obtained by deformation at $400^{\circ} \mathrm{C}$ up to strain of 0.7 at a strain rate of $1 \mathrm{~s}^{-1}$. Bear in mind that the scanned area is located between two particles.
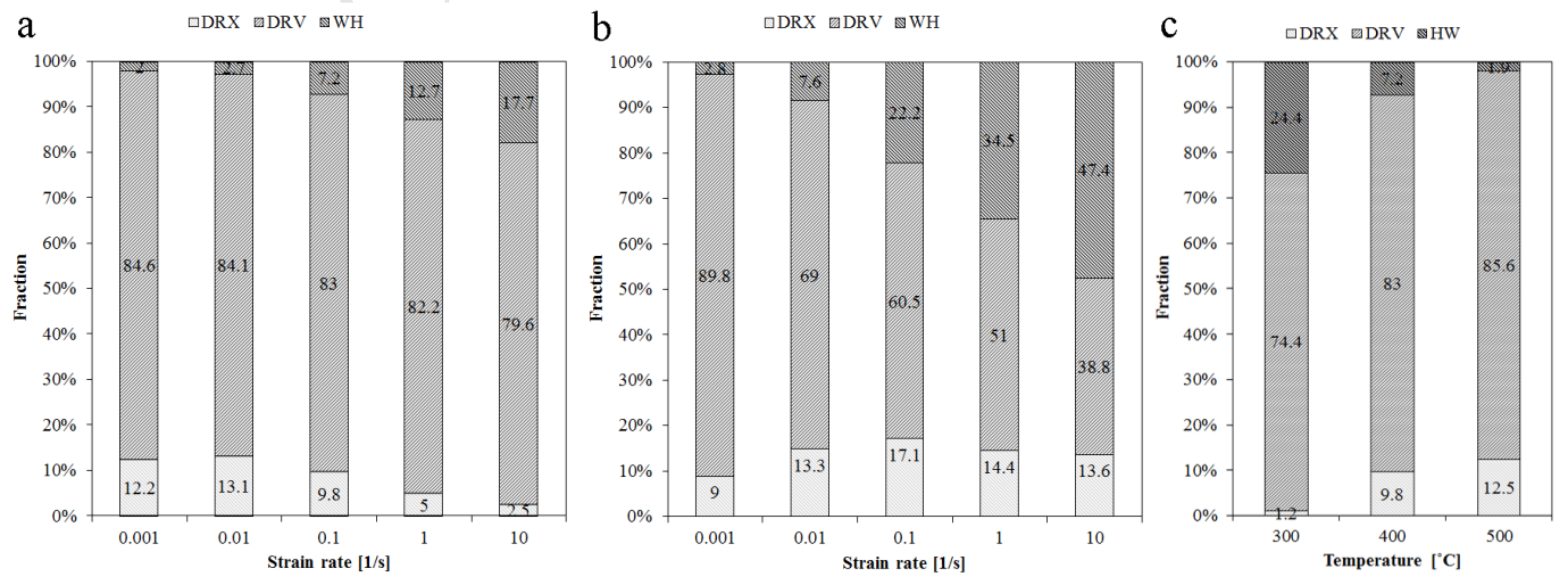
Fig. 7: Fraction of work hardened, dynamic recovered and dynamic recrystallized grains in the matrix (a) and around particles (b) for different strain rates at temperature of $400^{\circ} \mathrm{C}$ and in the matrix for different temperatures at a strain rate of $10^{-1} \mathrm{~s}^{-1}(\mathrm{c})$.

At high values of $Z$ (high strain rate), although DZs are well developed and situation is suitable for PSN mechanism, continuous recrystallization is limited. Therefore, only one mechanism is responsible for DRX. Another factor that can explain the limited DRX fraction at high strain rates is the short time for grain growth. Gourdet and Montheillet [26] indicated that in aluminum, because of a strong dislocation density differences between the two sides of a given grain boundary, the migration rate of grain boundaries is a power law function of strain rate, i.e., $d R / d t \propto \dot{\varepsilon}^{2 m}$, where $m$ is strain rate sensitivity. It is clear that for a constant strain, by increasing strain rate, the deformation time will be reduced by a factor $t \propto 1 / \dot{\mathcal{\varepsilon}}$. Therefore, if $m$ is less than 0.5 , which is normally the case during hot deformation of aluminum, by increasing strain rate, although migration rate increases, the time for growth is more reduced. As a result, microstructure contains smaller DRXed grains in the areas where the critical dislocation density has been achieved. In order to support this explanation, a comparison between amount and size of DRXed grains around particles is presented in Fig. 9.

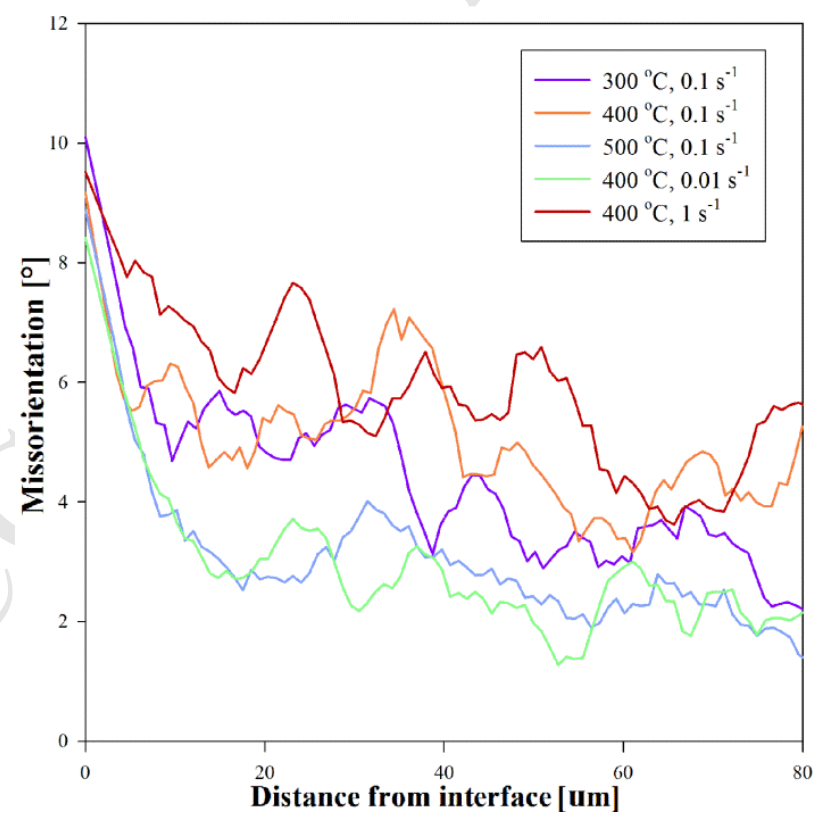

Fig. 8: Variation of misorientation from the particle-matrix interface to the matrix for different deformation conditions . 

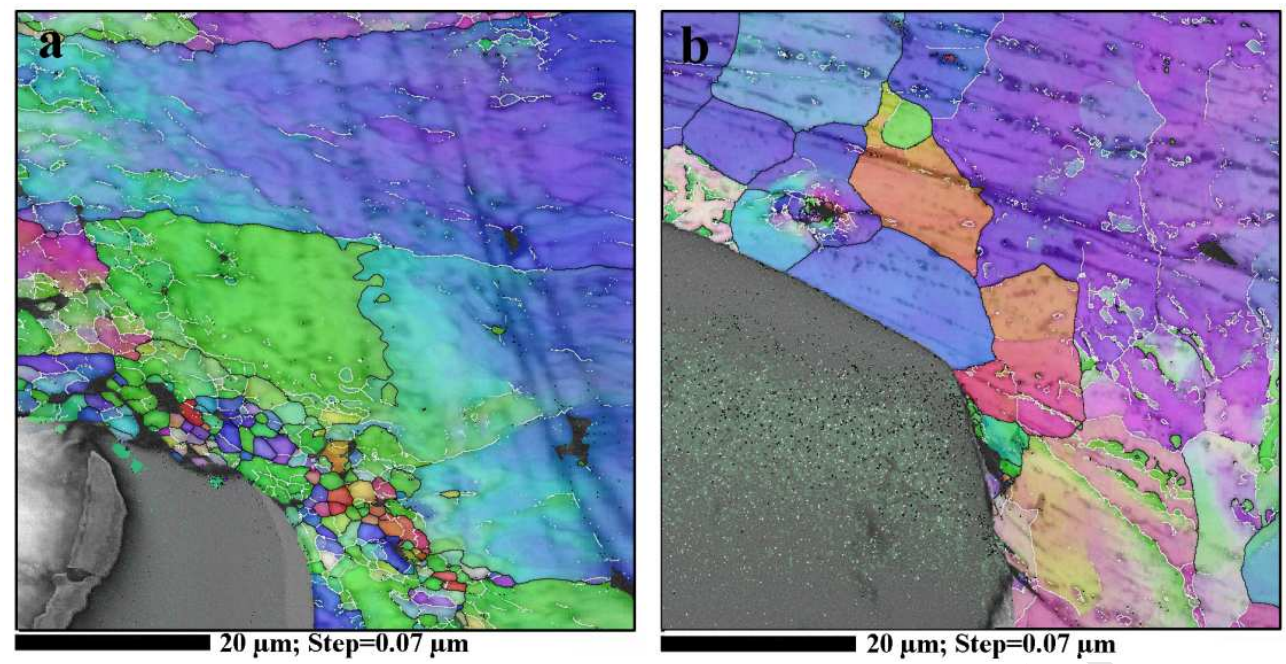

Fig.9: EBSD micrographs of samples deformed at $400^{\circ} \mathrm{C}$ with strain rates of (a) 10 and (b) $10^{-3} \mathrm{~s}^{-1}$.

\subsection{Grain refinement mechanisms - impact of temperature}

The results shown up to now concern with microstructural variations at different strain rates, but constant temperatures. As it is evident the restoration mechanism is also temperature dependent. [27]. According to Fig. 10, when deformation takes place at a lower temperature, i.e., $300{ }^{\circ} \mathrm{C}$, deformation zones are also formed around the particles. Moreover, the microstructure is formed by a heterogeneous distribution of LAGBs and elongated grains. In contrast, the microstructure deformed at $500^{\circ} \mathrm{C}$ displays recovered grains (with low aspect ratio) bordered by serrated boundaries and also some recrystallized grains. Subgrains are well developed which indicates a dominant role played by dynamic recovery and unlike deformation at lower temperatures, deformation zones which are characterized by workhardened grains around particles are not obvious.

Misorientation angle distribution graphs (Fig.10c and f) indicate that deformation at higher temperature results in more HAGB which can be explained in terms of the occurrence of DRX. As already stated, increasing temperature reduces the critical density required for DRX [25]. Moreover, grain boundary mobility $(M)$ is a function of temperature, i.e., $M=C \exp (-Q / R T)$ and hence, new grains can grow faster at higher temperature [28]. Therefore, it is reasonable that the microstructure deformed at higher temperature contains more and larger recrystallized grains (Fig. 7c).

High resolution EBSD micrographs reveal that some fine recrystallized grains $(\sim 1 \mu \mathrm{m})$ appear into the deformation zones in the vicinity of the particles even at $300^{\circ} \mathrm{C}$ (Fig. 10b). Considering their size and quenching time, these grains should be originated from the PSN 


\section{ACCEPTED MANUSCRIPT}

mechanism due to their formation in high energy areas. In the microstructure deformed at $500^{\circ} \mathrm{C}$, however, new grains are larger whether near or far from particles. In other words, it seems that PSN was not active during deformation at higher temperature, in a similar way to the observations when deformation took place at moderate temperature $\left(400^{\circ} \mathrm{C}\right)$ and low strain rate. In such conditions, a fast dynamic recovery process does not let to accumulate the required energy for the onset of recrystallization.
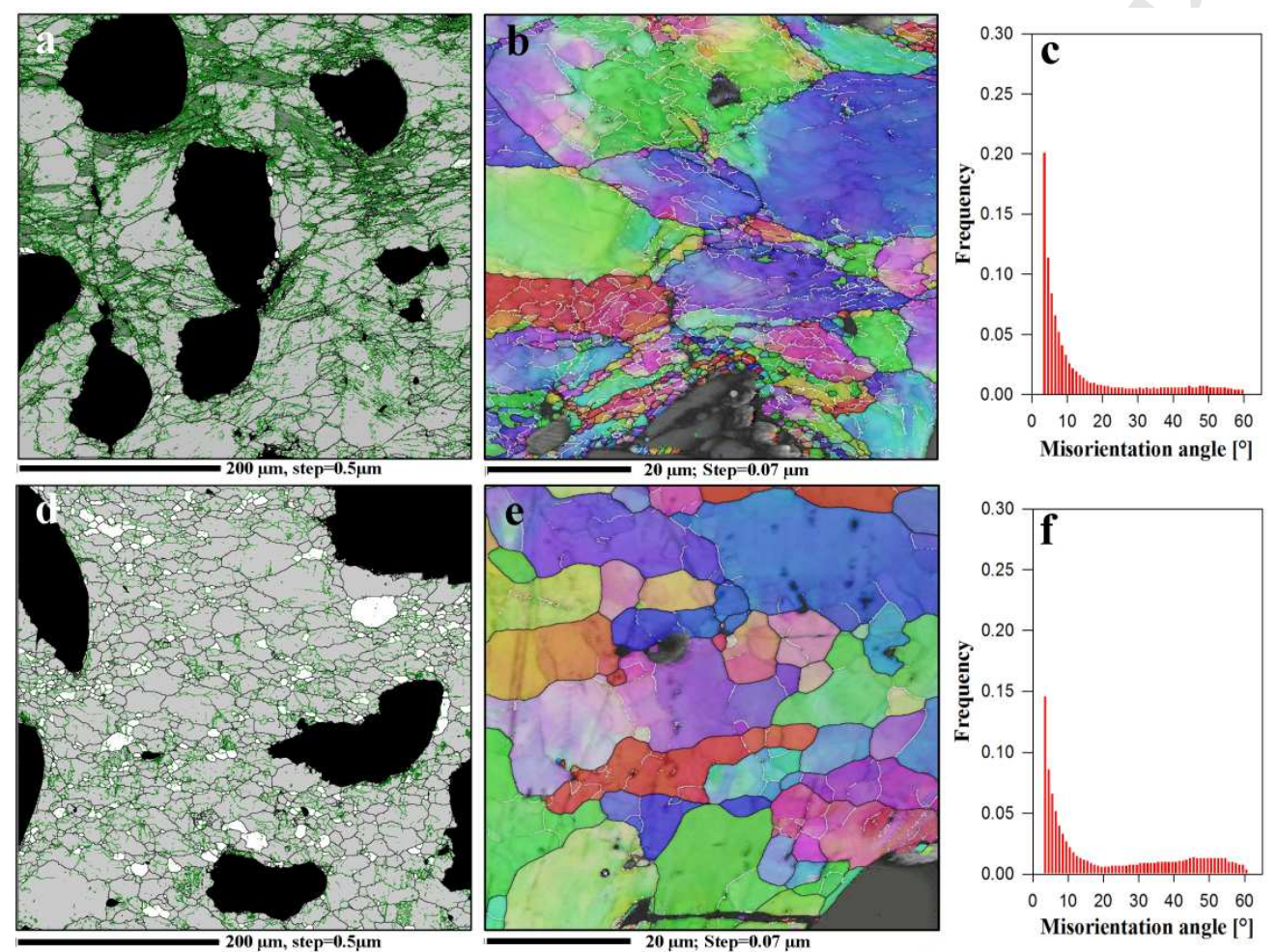

Fig. 10: EBSD micrographs and corresponding misorientation angle distribution of $\mathrm{Al}-3 \mathrm{Mg} / 10 \% \mathrm{~B}_{4} \mathrm{C}$ deformed at (a-c) $300^{\circ} \mathrm{C}$ and (d-f) $500^{\circ} \mathrm{C}$ with strain rate of $10^{-1} \mathrm{~s}^{-1}$.

\subsection{Grain and subgrain size description}

The dependence of the average subgrain size and DRXed grain size on de Zener-Holloman parameter is presented in Fig. 11. As it is obvious, by increasing $Z$, both subgrain size and recrystallized grains size decreases, especially at lower Zs values. A linear equation has been widely used to derive a relation between $\ln Z$ and subgrain size [2]. Applying this equation for the wide range of data obtained from micrographs is presented in Fig. 11. Based on this figure, it seems that although this equation is in acceptable agreement with data at low $Z$, is clearly not applicable at high $Z$ values. According to Murr [29], the relation of subgrain size and dislocation density is $d=k^{\prime} / \rho^{1 / 2}$, which by utilizing Taylor equation, $\sigma=M \alpha G b \rho^{1 / 2}$, can 
be related to stress. Considering the value of the stress during deformation, the relation between $Z$ and stress can be defined as a power function, i.e., $Z=k \sigma^{n}$. Therefore, the equation for determining subgrain size with respect to $Z$ parameter can be defined as:

$$
d=k^{\prime \prime} Z^{-\frac{1}{n}}
$$

where $n$ is the stress power exponent, which in turns is inverse of strain rate sensitivity, $m$, and based on active deformation mechanism varies from 3 to 7 (dislocation based deformation mechanisms). As a result, power of $Z(1 / \mathrm{n})$ should be between of 0.14 to 0.33 . As shown in Fig. 11, the value of $1 / n$ is 0.16 ( $n$ is around 6) which means that dislocation climb is the controlling mechanism during deformation. It should be noted that high strain rate results (black dots) are added to the graph after finding equation constants, to check if the presented equation is appropriate for predicting the average subgrain size at high $Z$. As it can be seen the experimental results are in agreement with model at high Zs. Applying this method on recrystallized grains also show better results in comparison with leaner approach (Fig. 11).
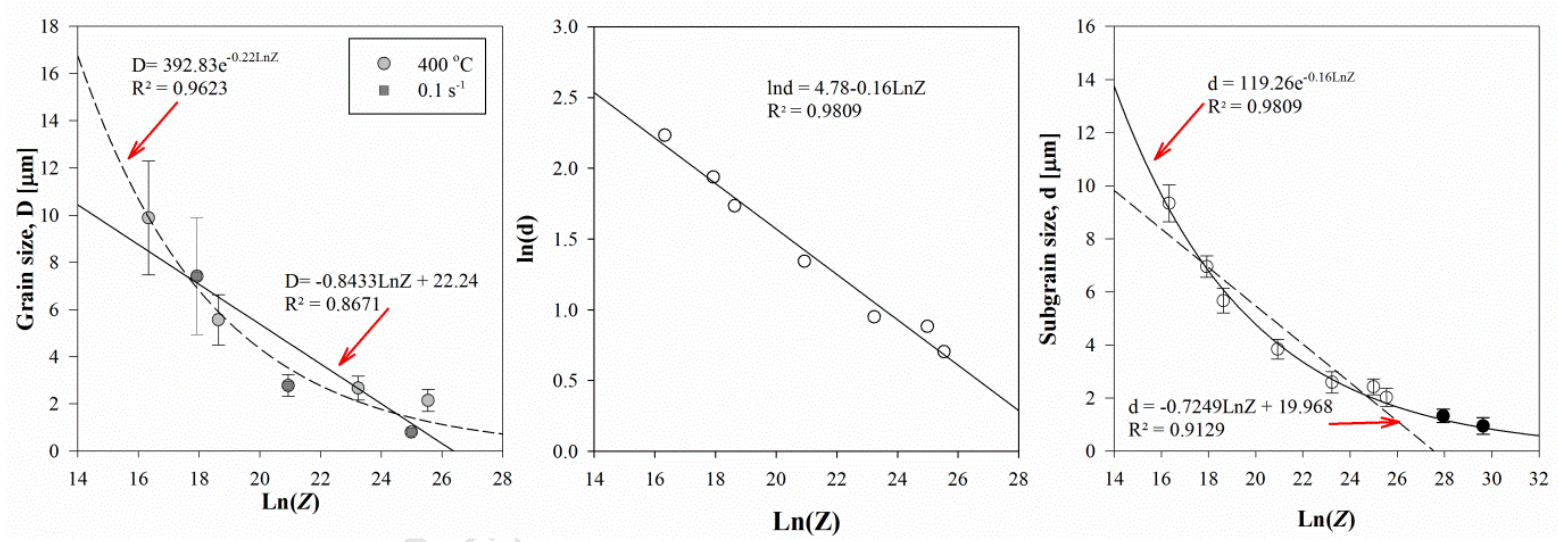

Fig.11: Dependence of the subgrain size $(d)$ and DRXed grain size $(D)$ on the $Z$ parameter. Note: black points are output of high temperature split Hopkinson pressure bar test which are reported elsewhere [8].

\section{Conclusion}

Al-3wt. $\% \mathrm{Mg}$ alloy reinforced with 10 vol. $\% \mathrm{~B}_{4} \mathrm{C}$ with particle size of around $80 \mu \mathrm{m}$ was deformed at temperatures of 300 to $500{ }^{\circ} \mathrm{C}$ with strain rates of $10^{-3}$ to $10^{1} \mathrm{~s}^{-1}$. Based on microstructural observations, the following conclusions can be drawn from this study:

1. At strain rates lower than $10^{-2} \mathrm{~s}^{-1}$ and temperatures higher than $400{ }^{\circ} \mathrm{C}$ the softening dominant mechanism was DRV, the microstructure near and far away from particles were uniform, and some DRX grains were appeared through lattice rotation mechanism. 
2. At higher strain rates up to $10 \mathrm{~s}^{-1}$, or temperatures lower than $400^{\circ} \mathrm{C}$, the microstructure far away from the particles was formed by DRVed grains, and near the particles it consisted of DRVed and DRXed grains as a result of the activation of the PSN mechanism. The large fraction of DRXed grains was observed at intermediate values of $\mathrm{Z}$.

3. The penetration of deformation zones formed around the particles into the matrix depends on the deformation condition, i.e., by decreasing $Z$, smaller deformation zone was formed.

4. At high value of $Z$ the average grain and sub-grain sizes of the composite material are lower than those in the single phase Al-Mg alloy, which is due to formation of highly deformed area occurrence of DRX in deformation zones close to the particles.

5. The variation of grain and sub-grain sizes for wide range of $Z$ was better described by a power law type equation instead of an exponential type.

\section{References}

[1] N. Chawla and K. Chawla, Metal matrix composite, Springer, 2006.

[2] F.J. Humphreys and M. Hatherly, Recrystallization and related annealing phenomena, Elsevier, 2004.

[3] H.J. Mcqueen and J.J. Jonas, "Recent advances in hot working: Fundamental dynamic softening mechanisms", Applied Metalworking, vol. 3, 1984, pp. 233-241.

[4] F.J. Humphreys, "The thermomechanical processing of A1-SiC particulate composites", Materials Science and Engineering A, vol. 135, 1991, pp. 267-273.

[5] F.J. Humpherys and P.N. Kalu, "Dislocation-particle interactions during high temperature deformation of two-phase aluminium alloys", Acta Metallurgica, vol. 35, 1987, pp. 2815-2829.

[6] K. Huang, K. Marthinsen, Q. Zhao, and R.E. Logé, "Progress in Materials Science The double-edge effect of second-phase particles on the recrystallization behaviour and associated mechanical properties of metallic materials", Progress in Materials Science, vol. 92, 2018, pp. 284-359.

[7] W. Xu, X. Jin, W. Xiong, X. Zeng, and D. Shan, "Study on hot deformation behavior and workability of squeeze-cast $20 \mathrm{vol} \% \mathrm{SiCw} / 6061 \mathrm{Al}$ composites using processing map", Materials Characterization, vol. 135, 2018, pp. 154-166. 
[8] M. Rezayat, M.H. Parsa, H. Mirzadeh, and J.M. Cabrera, "Dynamic deformation response of $\mathrm{Al}-\mathrm{Mg}$ and $\mathrm{Al}-\mathrm{Mg} / \mathrm{B} 4 \mathrm{C}$ composite at elevated temperatures", Materials Science and Engineering A, vol. 712, 2018, pp. 645-654.

[9] Y.li Li, W.-xian Wang, J. Zhou, and H.-sheng Chen, "Hot deformation behaviors and processing maps of $\mathrm{B}_{4} \mathrm{C} / \mathrm{A} 16061$ neutron absorber composites $\mathrm{B}_{4} \mathrm{C}$ particles", Materials Characterization, vol. 124, 2017, pp. 107-116.

[10] K. Wang, X. Li, Q. Li, G. Shu, and G. Tang, "A hot deformation behavior and microstructural evolution of particulate- reinforced AA6061 / B 4 C composite during compression at elevated temperature", Materials Science \& Engineering A, vol. 696, 2017, pp. 248-256.

[11] X.I.Y. An, J.P. Lin, Y. Lin, and T.Q. Lei, "Dynamic and metadynamic recrystallization in Al-Mg alloys", Materials Chemistry and Physics, vol. 20, 1988, pp. 275281.

[12] M. Muzyk, Z. Pakiela, and K.J. Kurzydlowski, "Ab initio calculations of the generalized stacking fault energy in aluminium alloys”, Scripta Materialia, vol. 64, 2011, pp. 916-918.

[13] K.T. Sona, M.H. Kim, S.-W. Kim, J.W. Lee, S.K. Hyun, "Evaluation of hot deformation characteristics in modified AA5052 using processing map and activation energy map under deformation heating", Journal of Alloys and Compounds, vol. 740, 2018, pp. 96108.

[14] G.A. Henshall, M.E. Kassner, and H.J. Mcqueen, "Dynamic restoration mechanisms in Al-5.8 at.pct $\mathrm{Mg}$ deformed to large strains in the solute drag regime", Metallurgical Transactions, vol. 23, 1992, pp. 881-889.

[15] H.J. Mcqueen, “Subgrain development in hot working of Al and Al-5Mg," Materials Science and Engineering A, vol. 5093, 1997, pp. 3-6.

[16] H. Chea, X. Jiang, N. Qiao, X. Liu, "Effects of $\mathrm{Er} / \mathrm{Sr} / \mathrm{Cu}$ additions on the microstructure and mechanical properties of Al-Mg alloy during hot extrusion", Journal of Alloys and Compounds, vol. 708, 2017, pp. 662-670.

[17] S. Agarwal, P.E. Krajewski, and C.L. Briant, "Dynamic recrystallization of AA5083 at $450^{\circ} \mathrm{C}$ : the effects of strain rate and particle size", Metallurgical and Materials Transactions A, vol. 39, 2008, pp. 1277-1289.

[18] T. Sheppard and M.G. Tutcher, "Development of duplex deformation substructure during extrusion of a commercial AI-5Mg-0.8Mn alloy," Metal Science, 1980, pp. 579-589. 
[19] K. Ihara and Y. Miura, "Dynamic recrystallization in Al-Mg-Sc alloys," Materials Science and Engineering A, vol. 389, 2004, pp. 647-650.

[20] W.M. Zhong, E. Goiffon, G.L. Esperance, M. Suery, and J.J. Blandin, "Effect of thermomechanical processing on the microstructure and mechanical properties of Al$\mathrm{Mg}(5083) / \mathrm{SiC}$ and $\mathrm{Al}-\mathrm{Mg}$ (5083)/A12O3 composite: Dynamic recrystallization of the composites," Materials Science and Engineering A, vol. 214, 1996, pp. 84-92.

[21] M. Rezayat, M.R. Bahremand, M.H. Parsa, H. Mirzadeh, and J.M. Cabrera, "Modification of As-cast Al-Mg / B4C composite by addition of Zr," Journal of Alloys and Compounds, vol. 685, 2016, pp. 70-77.

[22] T. Sakai, A. Belyakov, R. Kaibyshev, H. Miura, and J.J. Jonas, "Dynamic and postdynamic recrystallization under hot, cold and severe plastic deformation conditions," Progress in Materials Science, vol. 60, 2014, pp. 130-207.

[23] T.W. Clyne and P.J. Withers, An introduction to metal matrix composites, Cambridge University Press, 1995.

[24] M. Calcagnotto, D. Ponge, E. Demir, and D. Raabe, "Orientation gradients and geometrically necessary dislocations in ultrafine grained dual-phase steels studied by 2D and 3D EBSD,” Materials Science \& Engineering A, vol. 527, 2010, pp. 2738-2746.

[25] W. Roberts and B. Ahlblom, "A nucleation criterion for dynamic recrystallization during hot working," Acta Materialia, vol. 26, 1978, pp. 801-813.

[26] S. Gourdet and F. Montheillet, "Effects of dynamic grain boundary migration during the hot compression of high stacking fault energy metals," Acta Materialia, vol. 50, 2002, pp. 2801-2812.

[27] H. Mirzadeh, J.M. Cabrera, A. Najafizadeh, and P.R. Calvillo, "EBSD study of a hot deformed austenitic stainless steel," Materials Science \& Engineering A, vol. 538, 2012, pp. 236-245.

[28] Y. Huang and F.J. Humphreys, "Subgrain growth and low angle boundary," Acta Metallurgica, vol. 48, 2000, pp. 2017-2030.

[29] L.E. Murr and D.K. Wilsdorf, "Experimental and theoretical observations on the relationship between dislocation size, dislocation density, residual peak pressure and pulse duration shock-loaded," Acta Metallurgica, vol. 26, 1978, pp. 847-857. 


\section{Highlights}

1. Deformation at low Zs results in homogenous microstructure while at high Zs, PSN made it nonhomogeneous

2. At low Zs, lattice rotation DRX and at medium $Z$ s, discontinues DRX are responsible to grain refinement

3. Increase in $Z$ leads to penetrate deformation zones from around particles into the matrix

4. A power law type equation is developed to predict grain or sub-grain sizes for wide range of $Z$ 